\title{
Comprehensive Approach to Public Lighting
}

\begin{abstract}
Public lighting as well as every technical infrastructure has got its own lifetime, so the periodic renovation is needed. Public lighting in the Czech Republic was built during the 70's of the last century and regular renovations were done only in larger cities. In small cities and villages, the public lighting systems are almost at the end of their life time and it is necessary to make the overall reconstruction. For a long time, relatively a little attention was paid to public lighting. The situation was changed in the last few years, where thanks to the pressure to lower the energy consumption, the attention was focused also on the public lighting. Solutions of problems with energy efficiency are usually accompanied by financial instruments in the form of subsidies, grants etc. which support the change of technical equipment with low efficiency for technical equipment with high efficiency. However, in above mention steps the considerations of the overall reconstruction of public lighting is missing. With reference to situation in public lighting systems it would be appropriate to combine their energy performance solutions with overall reconstruction. Older lighting systems and unfortunately, also some new lighting systems, are not only energy inefficient but in many cases they also visually disturb public spaces by their location, design or proportions. In addition, they are the sources of obtrusive light too. Public spaces are important part of human settlements and the scale of life quality. The light is an instrument for creating environment with regards to many aspects (cultural, historical, functional, etc.) of urban areas. It is necessary to perceive public lighting comprehensively taking into account not only the traffic safety and energy consumption but also architectural-urban aspects and aspects connected with minimizing of obtrusive light.
\end{abstract}

Keywords: public lighting, public spaces, lighting master plan, lighting design, obtrusive light

\section{Introduction}

Currently, while addressing the issues of public lighting, it is quite often possible, and not only in small municipalities, to encounter certain helplessness on how to proceed. The following paper gives one of the possible approaches to the solution of this issue.

The quality of public lighting is related to how the whole issue is viewed. Most often, the image of public lighting is created through the media and in various advertising campaigns within which the whole issue is often reduced only to certain topics. For example, in the past, such a topic was light pollution. Nowadays, it is energy and costs savings, grants, LED lighting, green technologies, luminaires consumption etc. The above mentioned topics do not cover the whole issue, but only its limited part. This simplification is misleading and very dangerous since it distracts the attention from the issue of public lighting as a whole. This may ultimately lead not only to an inefficient use of financial resources and degradation of public spaces, but also to the lowering of traffic safety. With regards to the costs and lifetime of the public lighting system, any unsuitable steps in this area may lead to long-term negative effects, or they may require significant financial resources in order to repair the problems.

The purpose of public lighting is not to achieve the lowest energy consumption, nor to have sophisticated lighting system optimization not even to introduce green technologies or to use control systems. The primary purpose of lighting is to ensure the safety of people, property and transport. In addition, it is also a factor that significantly affects the appearance and atmosphere of public spaces in the nighttime and also in daytime. It affects the identification of local residents with the environment in which they live, as well as the attractiveness of the municipalities from visitors' perspective. Public lighting is also quite complex, extensive and expensive technical infrastructure, which includes not just luminaires, but also supporting structures (poles, arms, etc.) power lines and switchboards. The quality of public lighting is related not only to the quality of physical elements and light environment which is thus created, but also to the activities (design, realization, maintenance, operation, etc.) and to the people who influence the form of public lighting. (Fig.1).
Public lighting is being constantly developed from the technical point of view. Also, it keeps being extended according to the expansion of the municipality. To preserve the quality of public lighting, maintenance must be done. Moreover, since some parts of public lighting have a limited lifetime regular reconstructions of certain parts are required. It is a continuous long-term process that involves many people and organizations. If, in this process, we want to reach a stable quality level and to prevent the situation, in which public lighting system will become a set of inhomogeneous elements, the issue of public lighting should be solved in comprehensive way, by creating certain order and rules.

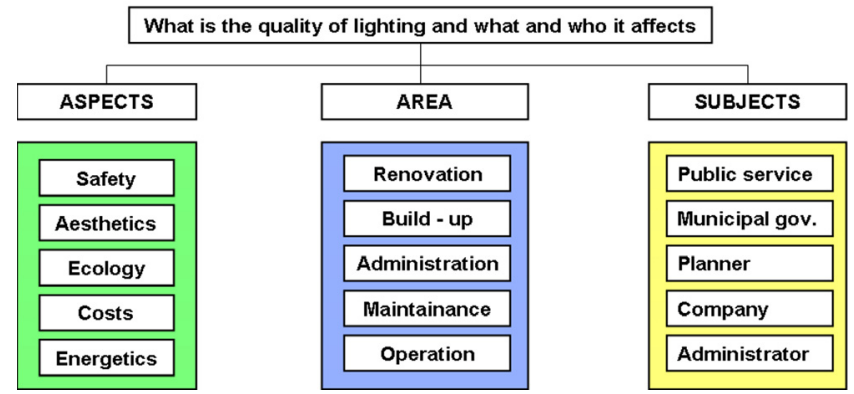

Fig. 1. Factors affecting the quality of public lighting

Without a conceptual approach, it is very difficult to find a solution in which the public lighting fulfills its primary function and simultaneously, it is energy efficient, creates a pleasant environment, does not disturb its surroundings and holds the quality, which corresponds to the investments and operating costs.

\section{Public lighting concept}

Conceptual approach to the public lighting includes several essential steps. Therefore, in order to begin the process of consideration of the public lighting solution, the municipality must firstly analyze the current state. In the next step, it is necessary to determine what the municipality expects from the public lighting and to create a vision of the urban spaces appearance in the nighttime. Finally, it is necessary to create a schedule of the public lighting reconstruction and to set up the quality standards of the products and activities related to the public lighting. Given 
intellectual structure of a comprehensive solution of the public lighting can be translated into a set of documents under the name of Public lighting concept, which should include at least the following documents:

- Public lighting passport;

- Analysis of current state;

- Lighting master plan;

- Plans of reconstruction and modernization;

- Standard of activities and products.

Public lighting passport is a record, which contains information on elements of the public lighting systems, such as position, technical parameters, identification, age, or records of changes. Analysis of the current state creates a comprehensive picture of the actual status of public lighting in terms of its structure, age and condition of individual elements, costs and energy consumption, and in terms of control and power supply, geometric layout and photometric parameters. Lighting master plan is an architectural, urban and lighting study that describes the appearance of the city in the evening and during night hours. It creates a framework of technical solutions by specification of the lighting parameters for individual public spaces, streets, roads and objects. This framework is designed to ensure that all interventions into the public lighting (reconstruction, development, maintenance, operation etc.), will be coordinated and consistent with the idea of proposed night appearance of individual public spaces and the entire city. The plan of reconstruction, based on information about the current state of public lighting, includes time schedule for replacement of public lighting elements in the current quality standards, so their physical lifetime is not exceeded. The plan of modernization, based on the design of a new lighting system which incorporates innovative features and solutions, contains timetable for upgrading of public lighting system and its parts, which will lead to higher quality and $/$ or cost savings. The plan of reconstruction and modernization is a tool for the efficient spending of the financial resources in public lighting. The standard of products is a document that includes a clear definition of specific products for the reconstruction and modernization of public lighting to avoid uncontrolled type diversity of public lighting elements. The standard of activities includes definitions and descriptions of activities associated with public lighting (planning, build-up, operation, maintenance, etc.), set the inputs, outputs and quality requirements so these activities can be easily monitored.

Another part of the paper deals in detail with the lighting design from architectural and urban point of view and its role in lighting master plan.

\section{Light - tool for creation of urban spaces}

Each settlement has its own distinctive character and its spatial composition that affects movement and residence of locals and visitors. According to Christian Norbert Schulz, the structure of place has to be described in categories "landscape" and "settlement" and analyzed in categories of "space" and "character". While the "space" refers to the three-dimensional organization of the elements that make the place, "character" refers to the overall atmosphere, which is a characteristic of each settlement [1].

Since the Early Middle Ages, each town has undergone a long and complicated development. Within a few centuries, their original urban form transformed and changed many times. Their development always followed the previous urban layout, which includes the original historical basis; more or less joined into a harmonious totality [2]. The quality of public spaces has always contributed to the quality of life in towns and villages, because the quality of the town is given by the relationships inside it. Due to the fact that people use public spaces also at nighttime, the artificial light allows the perception of public spaces. For this reason the public lighting is an essential tool for the creation of urban spaces. Public lighting affects the appearance and character of public spaces with their photometric and physical parameters. The composition of public spaces and spaces in various settlements usually form a complete system of interconnected and interrelated publicly accessible locations that have different character depending on the historical development of the territory, pedestrians, location, town amenities, functional content of individual spaces, etc. This system is should be maintained in the evening and at nighttime through the public lighting. By suitable choice of the public lighting character, the appearance of lighting system and by the design of architectural lighting, it is possible in certain way to substitute daylight and to promote the perception of public spaces as required.

Light is an important tool in creation of an emotional environment. Architects are trying to create such urban areas, which will serve to residents and visitors, depending on the nature of space. Light can affects not only the atmosphere of the place, the concentration of people, movement and orientation of users, but also the moods and feelings of the people. Conceptual approach to public lighting requires cooperation between an architect, who designs nighttime appearance of public spaces, and lighting engineer, who proposes how the idea of the nighttime appearance should be realized.

\section{Lighting master plan}

Lighting master plan is understood here as an architectural, urban and lighting study that describes the appearance of the municipality at nighttime. This document works with light and lighting, not only in terms of the requirements for the safety of persons, property and transport, but also in terms of appearance and atmosphere of public spaces and in terms of obtrusive light limitation. In architectural and urban part of the lighting master plan the nighttime appearance of the city is designed, and in the lighting technical design part of the document the idea is transformed into the technical parameters, which describe the lighting environment and the lighting system. In order to maintain timeliness character of this document, it is appropriate to use the parameters that are not dependent on the development of technology. In the lighting master plan it is also advisable to choose a varied degree of parameters flexibility depending whether it is a standard public space, where architect's cooperation on the public lighting reconstruction is not expected or whether it is a major public space (squares, historic center, walking zones, etc.), where the participation of the architect is expected. In this case, it is advisable to have looser rules, which will not prevent the original solutions.

\section{Architectural and urban lighting design}

Public lighting system affects the perception of the public space by its photometric parameters and physical properties. The main photometric parameters include: amount of the light, composition of the light and spectral (color) properties of the light [3]. The amount of light means the level of luminance or illuminance on surfaces forming the public space. This parameter can affect the hierarchy of spaces at night and emphasize the importance of core areas, respectively spatial or functional viewpoints.

From an architectural and urban point of view, the composition of the light is very important lighting parameter 
to work with public spaces. Artificial light emitted by public and architectural lighting provides visual information at nighttime, and determines the spatial perception of public spaces. Is it possible to determine what will be seen, what will not be seen, and how the space will be perceived, whether the entire or part of space will be illuminated. Figure 2 and fig. 3 shows the difference between a place which is illuminated entirely and partially. Fig. 2 shows illumination on both horizontal and vertical surfaces. Space has a comprehensive form; it is possible to perceive the overall definition of space. In addition, a different level of luminance on individual objects allows identification of their significance. In contrast, in the space in fig. 3 the observer can hardly see the different parts of space, its border, and also, the overall orientation is difficult.

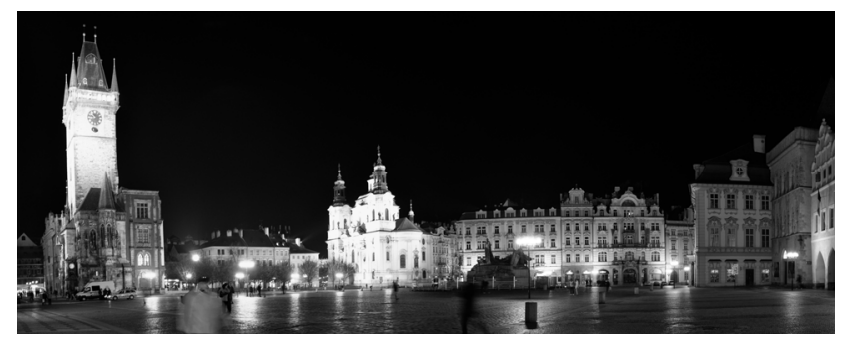

Fig. 2. Lighting composition, Old Town Square, Prague, Czech Republic

The color of light significantly affects the atmosphere of the environment. Warm colors generally evoke a sense of quiet and warmth. They contain relaxation within themselves together with an emotional component, which is the color of fire - the symbol of safety and warmth of domesticity. Conversely, cool colors evoke increased attention and activity of observers. The color of light is also a tool to highlight a certain place, part of the space or object, to distinguish the nature or operation of public spaces. Inappropriate choice of light color tone can suppress genius loci of the place and its spontaneity in the nighttime.

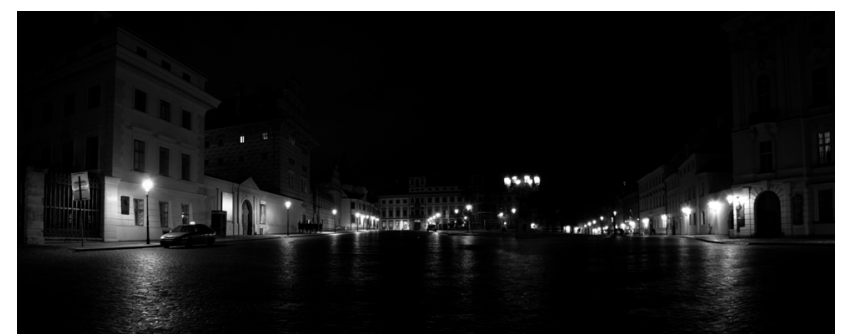

Fig. 3. Lighting composition, Hradcany Square, Prague, Czech Republic

Physical properties of light points have significant impacts on the appearance of public space during the daytime. This is the appearance of light points and their location in space. The actual appearance of the light points is to be chosen in relation to the space which is illuminated.

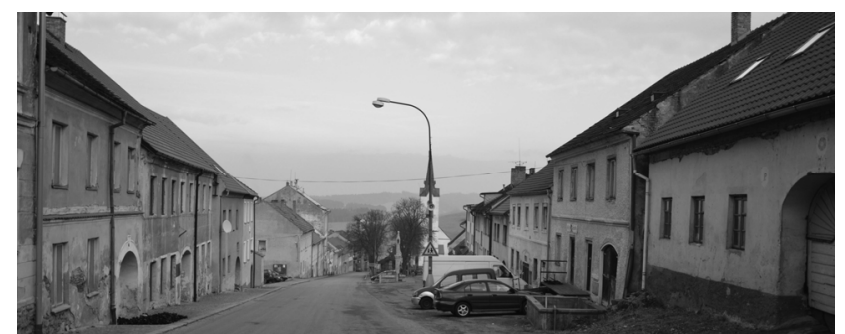

Fig. 4. Improper placement of the light point in the visual axis on the cultural landmark, Horice na Sumave, Czech Republic.
Each public space has its limits regarding the typology, height, proportion, scale and color and material design of lighting points. It is necessary to respect the visual axis in the settlements and in the landscape, cultural values and individual character of public spaces, so that the lighting system is not applied in visual axes, not to interfere with the visual and spatial relationships, and not to cast a shadow and not to create physical barriers. Example of improper placement of the light point is shown in Fig. 4.

\section{Technical design of lightning}

Technical part of lighting master plan deals with the lighting from the perspective of safety and security of the people, transport and properties. Roads, street and public spaces are, based on operation characteristic, placed to the lighting classes. Given that these characteristics may vary during the night, it is appropriate to propose operating modes for each road and public space which will respond to these changes. Since the operation of public lighting can disturb it's surrounding, it is necessary, to classify public spaces into the environmental zones based on the sensitivity to artificial light. Finally, the lighting parameters are assigned to all public spaces, roads, streets and objects both in terms of architectural and urban lighting design, and in terms of traffic safety, operating characteristics and limitations of disturbing effects of lighting. This information is the basis for the subsequent stages of the project documentation for reconstruction and development of public and architectural lighting. An example of map outputs of lighting master plan is shown in Fig. 5.

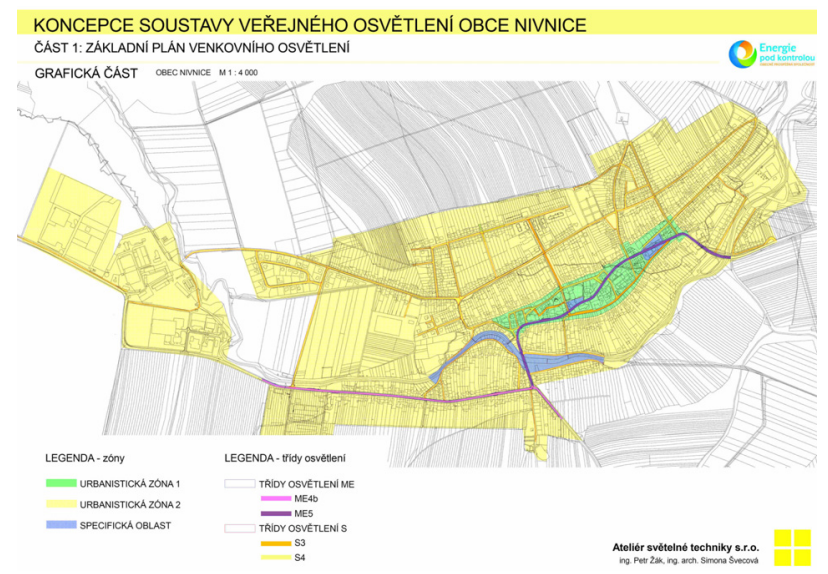

Fig. 5 Map of Lighting master plan, Nivnice, Czech Republic

\section{REFERENCES}

[1] Norberg-Schulz, Ch.: Genius loci: krajina, místo, architektura. 2. vyd. Překlad Petr Kratochvíl, Pavel Halík. Praha: Dokořán, 2010, 219 s. ISBN 978-80-7363-303-5.

[2] Sojková E.: Zeleň městských památkových zón Středočeského kraje. Průhonice: Výzkumný ústav Silva Taroucy pro krajinu a okrasné zahradnictví, 2014, 119 s. ISBN 978-80-87674-06-2.

[3] Monzer L., Novotný J.: Osnova generelního řešení osvětlení venkovních prostorů Pražského hradu,Tesla Holečovice n.p., Praha, 1972.

\section{Authors:}

Ing. Petr Žák, Ph.D.,

Czech Technical University in Prague, Faculty of Electrical Engineering, Department of Electroenergetics, Technická 2, 16629 Prague 6, Czech Republic,

e-mail: zakpetr@fel.cvut.cz ,

Ing. arch. Simona Švecová, Czech Technical University in Prague, Faculty of Civil Engineering, Department of Urban Design, Town and Regional Planning, Thákurova 6, 166 29, Prague 6, Czech Republic,

e-mail: simona.svecova@fsv.cvut.cz. 